\title{
BCL-2 Family protein expression in initial and recurrent glioblastomas: modulation by radiochemotherapy
}

H Strik, M Deininger, J Streffer, E Grote, J Wickboldt, J Dichgans, M Weller, $\mathrm{R}$ Meyermann

\begin{abstract}
Objective-In vitro studies indicate a role of apoptosis regulatory proteins of the BCL-2 family in the resistance of glioblastoma multiforme to irradiation and chemotherapy. To date, no study has compared the expression of these proteins in initial and recurrent tumours. The differences of expression of BCL-2, BCL-X, $B A X$, and MCL-1 proteins of paired first resection and recurrence glioblastoma specimens were examined.
\end{abstract}

Methods-Immunohistochemistry was performed in 37 cases of glioblastoma multiforme with paraffin embedded tissue from first resections and their recurrences in three treatment groups (15 radiochemotherapy, 15 irradiation, seven untreated). Ten high power fields were evaluated with an arbitrary score (< $5 \%=1,5-50 \%=2,>50 \%=3)$, and cumulative scores for each antigen calculated.

Results-In the whole group, we found a significant up regulation of antiapoptotic BCL-2 (median cumulative score of 15 in the primary, 19 at recurrence; $p<0.0001$ in the Wilcoxon test), BCLX (median scores 20 and 25 , respectively, $p<0.0001$, and MCL-1 (median scores 11 and 14, $p=0.0395$ ), and a significant down regulation of proapoptotic BAX (median scores 14 and $11, p<0.0001)$. In the subgroups, these trends were also found. No association between protein expression and treatment regimen was found, although significant changes were restricted to the subgroups that received adjuvant chemotherapy. No significant correlation with clinical prognosis was detected with the Kaplan-Meier method.

Conclusions-In the development from initial to recurrent glioblastoma multiforme, the BCL-2 family rheostat shifts towards antiapoptotic adjustment in vivo. Importantly, the changes in BCL-2 family protein expression characterised here were also seen in the subgroup of patients who did not receive adjuvant radiotherapy or chemotherapy, suggesting that the changes of BCL-2 family protein expression result not only from radiochemotherapy but also reflect the natural course of disease.

(F Neurol Neurosurg Psychiatry 1999;67:763-768)

Keywords: glioblastoma; apoptosis; BCL-2
Glioblastoma multiforme is highly malignant with a marked resistance to anticancer treatment. Clinical prognostic factors such as tumour size and extent of resection, age, and Karnofsky performance status are relatively well determined. ${ }^{12}$ By contrast, no biological marker with impact on clinical prognosis is known to date. For instance, p53 has not been confirmed as a prognostic marker in malignant glioma. ${ }^{3}$

The efficacy of adjuvant therapy is limited. Regulators of apoptosis such as p53 and BCL-2 family proteins determine the cellular fate of survival or death after DNA damage induced by irradiation or chemotherapy. BCL-2, BCL-xL (a splicing product of BCL$\mathrm{X}), \mathrm{MCL}-1$, and other BCL-2-related proteins are inhibitors of apoptosis, whereas BAX, BCL-xS (another splicing product of BCL-X), and other proteins such as BAD and BAK promote cell death. In vivo, antiapoptotic BCL-xL is by far the most abundant splice variant present in all tissues tested. ${ }^{4}$ BCL-2 family proteins interact by homo and heterodimerisation. ${ }^{5}$ A rheostat between proapoptotic and antiapoptotic proteins may regulate the susceptibility to death promoting stimuli.

Proteins of the BCL-2 family are thought to contribute to the resistance of glioma cells to anticancer therapy by modulating the apoptotic cascade. For instance, BCL-2 gene transfer into human malignant glioma cells blocked CD95 antibody mediated apoptosis and conferred resistance to chemotherapeutic drugs and irradiation. ${ }^{6}$ The activity of BCL-2 family proteins can be altered by irradiation and chemotherapy. In glioma cell lines expressing wild-type p53, a decrease of BCL-2 and increase of BAX concentrations was found after exposure to camptothecin. ${ }^{7}$ To date, no long term effects of radiochemotherapy on BCL-2 family protein expression have been reported. Few data on the clinical impact of BCL-2 in malignant gliomas have been published. ${ }^{-11}$ One study examining the prognostic impact of BCL-X, MCL-1, and BAX in glioblastoma multiforme found a better prognosis in patients with low MCL-1 expression. ${ }^{12}$

Here, we compared the expression of BCL-2 related proteins in initial and recurrent glioblastoma multiforme in vivo, examined a possible influence of multimodal anticancer treatment on protein expression, and considered whether protein expression and progression free survival were correlated. 
Table 1 Patient data and cumulative scores

\begin{tabular}{|c|c|c|c|c|c|c|c|c|c|c|c|c|c|}
\hline \multirow[b]{2}{*}{ Patient } & \multirow[b]{2}{*}{ Age } & \multirow[b]{2}{*}{ Sex } & \multirow{2}{*}{$\begin{array}{l}\text { Radiation } \\
\text { Gy }\end{array}$} & \multirow{2}{*}{$\begin{array}{l}\text { Chemoth No } \\
\text { courses }\end{array}$} & \multicolumn{2}{|c|}{$B C L-2$} & \multicolumn{2}{|c|}{$B C L-X$} & \multicolumn{2}{|l|}{$B A X$} & \multicolumn{2}{|c|}{$M C L-1$} & \multirow{2}{*}{$\begin{array}{l}\text { PFS } \\
\text { Months }\end{array}$} \\
\hline & & & & & Prim & $\operatorname{Rec}$ & Prim & $\operatorname{Rec}$ & Prim & $\operatorname{Rec}$ & Prim & $\operatorname{Rec}$ & \\
\hline 1 & 60 & $\mathrm{~F}$ & 60 & $5 \mathrm{AC} / \mathrm{Ara}-\mathrm{C}$ & 15 & 29 & 12 & 19 & 11 & 11 & 11 & 10 & 11 \\
\hline 2 & 53 & $M$ & 60 & $2 \mathrm{AC} / \mathrm{VM} 26$ & 12 & 13 & 15 & 20 & 21 & 11 & 13 & 11 & 12 \\
\hline 3 & 43 & $M$ & 60 & $5 \mathrm{AC} / \mathrm{Ara}-\mathrm{C}$ & 21 & 23 & 18 & 26 & 11 & 10 & 15 & 16 & 27 \\
\hline 4 & 40 & $M$ & 60 & $3 \mathrm{AC}$ & 14 & 18 & 24 & 28 & 12 & 10 & 10 & 10 & 8 \\
\hline 5 & 43 & M & 60 & $2 \mathrm{CC}$ & 21 & 25 & 30 & 30 & 16 & 14 & 16 & 20 & 11 \\
\hline 6 & 27 & $M$ & 60 & $2 \mathrm{AC} / \mathrm{VM} 26$ & 12 & 11 & 11 & 28 & 10 & 10 & 10 & 10 & 3 \\
\hline 7 & 57 & M & 60 & $3 \mathrm{CC}$ & 11 & 17 & 25 & 17 & 16 & 11 & 10 & 10 & 6 \\
\hline 8 & 51 & M & 50.4 & $2 \mathrm{AC} / \mathrm{VM} 26$ & 17 & 18 & 22 & 24 & 16 & 10 & 10 & 13 & 4 \\
\hline 9 & 54 & $M$ & 60 & $5 \mathrm{AC}$ & 14 & 19 & 15 & 24 & 12 & 11 & 10 & 10 & 30 \\
\hline 10 & 55 & M & 60 & $2 \mathrm{AC} / \mathrm{VM} 26$ & 14 & 21 & 12 & 28 & 10 & 13 & 10 & 13 & 13 \\
\hline 11 & 38 & M & 60 & $6 \mathrm{AC}$ & 14 & 11 & 12 & 15 & 10 & 10 & 10 & 10 & 46 \\
\hline 12 & 34 & $\mathrm{M}$ & 60 & $7 \mathrm{AC} / \mathrm{VM} 26$ & 10 & 20 & 12 & 25 & 10 & 11 & 10 & 13 & 16 \\
\hline 13 & 52 & $\mathrm{~F}$ & 60 & $1 \mathrm{AC}$ & 13 & 19 & 24 & 25 & 18 & 12 & 11 & 11 & 19 \\
\hline 14 & 47 & $M$ & 60 & $2 \mathrm{AC} / \mathrm{Ara}-\mathrm{C}$ & 15 & 20 & 26 & 29 & 15 & 11 & 12 & 10 & 12 \\
\hline 15 & 53 & M & 60 & $4 \mathrm{AC}$ & 13 & 20 & 20 & 20 & 15 & 11 & 10 & 17 & 9 \\
\hline 16 & 52 & $M$ & 60 & No & 15 & 16 & 23 & 22 & 14 & 14 & 10 & 10 & 12 \\
\hline 17 & 60 & $\mathrm{~F}$ & 54 & No & 10 & 15 & 14 & 17 & 13 & 12 & 10 & 11 & 12 \\
\hline 18 & 57 & M & 60 & No & 14 & 20 & 23 & 30 & 14 & 12 & 13 & 17 & 6 \\
\hline 19 & 56 & $M$ & 60 & No & 13 & 18 & 20 & 27 & 10 & 12 & 10 & 12 & 36 \\
\hline 20 & 38 & M & 55 & No & 15 & 14 & 19 & 30 & 11 & 19 & 10 & 19 & 7 \\
\hline 21 & 50 & $M$ & 60 & No & 22 & 20 & 21 & 30 & 19 & 14 & 11 & 13 & 12 \\
\hline 22 & 46 & $M$ & 60 & No & 17 & 28 & 21 & 30 & 14 & 10 & 10 & 11 & 7 \\
\hline 23 & 66 & $\mathrm{~F}$ & 60 & No & 15 & 16 & 16 & 18 & 13 & 12 & 10 & 10 & 11 \\
\hline 24 & 46 & $\mathrm{M}$ & 54 & No & 16 & 26 & 30 & 30 & 14 & 16 & 11 & 15 & 18 \\
\hline 25 & 59 & M & 60 & No & 24 & 25 & 26 & 26 & 14 & 10 & 10 & 10 & 4 \\
\hline 26 & 56 & $\mathrm{~F}$ & 38 & No & 10 & 16 & 11 & 21 & 11 & 11 & 10 & 11 & 2 \\
\hline 27 & 48 & $M$ & 60 & No & 19 & 14 & 25 & 20 & 16 & 12 & 13 & 10 & 7 \\
\hline 28 & 49 & $M$ & 60 & No & 22 & 26 & 13 & 17 & 10 & 10 & 10 & 13 & 3 \\
\hline 29 & 67 & $M$ & 60 & No & 13 & 17 & 16 & 17 & 14 & 10 & 10 & 13 & 16 \\
\hline 30 & 45 & $\mathrm{~F}$ & 60 & No & 11 & 14 & 14 & 15 & 11 & 11 & 11 & 11 & 20 \\
\hline 31 & 51 & $M$ & No & No & 13 & 10 & 18 & 11 & 11 & 12 & 10 & 10 & 7 \\
\hline 32 & 16 & $M$ & No & No & 15 & 25 & 27 & 26 & 21 & 17 & 22 & 11 & 1 \\
\hline 33 & 79 & $\mathrm{~F}$ & No & No & 15 & 27 & 17 & 23 & 11 & 13 & 11 & 11 & 6 \\
\hline 34 & 61 & $\mathrm{~F}$ & No & No & 15 & 11 & 22 & 29 & 15 & 12 & 14 & 15 & 1 \\
\hline 35 & 54 & $M$ & No & No & 12 & 17 & 20 & 30 & 12 & 12 & 11 & 14 & 3 \\
\hline 36 & 49 & $M$ & No & No & 17 & 22 & 30 & 30 & 18 & 21 & 17 & 13 & 8 \\
\hline 37 & 61 & $\mathrm{~F}$ & No & No & 20 & 29 & 22 & 29 & 15 & 10 & 11 & 11 & 8 \\
\hline
\end{tabular}

$\mathrm{AC}=\mathrm{ACNU}, \mathrm{CC}=\mathrm{CCNU} ; \mathrm{PFS}=$ progression free survival; prim=primary; rec=recurrent.

\section{Materials and methods}

PATIENT DATA

We collected consecutive cases with paraffin embedded tissue from initial and recurrent glioblastoma multiforme in the same patient. Starting from 1985, 37 cases were eligible for examination by immunohistochemistry. Patient data are shown in table 1.

All specimens of the primary tumours were obtained before radiotherapy or chemotherapy. Tissue samples were divided into three treatment groups: 15 patients were treated with radiotherapy with an average dose of 57.4 Gy. Another 15 patients received adjuvant chemotherapy in addition to radiotherapy (mean 59.4 Gy). Chemotherapy regimens were not standardised, but always contained a nitrosourea (ACNU or CCNU) as a single agent or combined with either Ara-C or VM 26 (table 1). Seven patients received not more than one or two chemotherapy courses, due to haematological complications or early recurrence. Seven other patients refused any specific postoperative treatment (table 2).

Table 2 Patient data in treatment groups

\begin{tabular}{lllll}
\hline & Whole group & Radiochemotherapy & Radiotherapy & Untreated \\
\hline Patients & 37 & 15 & 15 & 7 \\
Mean age (SEM) (y) & $51(1.87)$ & $47(2.4)$ & $53(2.09)$ & $53(7.23)$ \\
Female & 12 & 4 & 5 & 3 \\
Male & 25 & 11 & 10 & 4 \\
Radiation (mean dose) & 30 patients & 57,4 Gy & 59,4 Gy & No \\
Chemotherapy & 15 patients & ACNU/CCNU & No & No \\
& & \pm Ara-C/VM26 & & \\
\hline
\end{tabular}

IMMUNOHISTOCHEMISTRY

Paraffin embedded samples were cut, deparaffinised, and rehydrated. The $3 \mu \mathrm{m}$ sections were immersed in $0.01 \mathrm{M}$ citrate buffer and irradiated for $5 \times 5$ minutes in a microwave oven set at 750 W. Endogenous peroxidase was blocked with $1 \% \mathrm{H}_{2} \mathrm{O}_{2}$ in methanol. Nonspecific protein binding domains were blocked by application of standard porcine serum (Seromed $\AA$, Biochrom, Berlin, Germany) for 15 minutes. Monoclonal antibodies to BCL-2 (Clone 124, monoclonal, Dakopatts, Glostrup, Denmark) and polyclonal antibodies to BCL-X (BCL-xL and BCL-xS), BAX and MCL-1 (BCL-X L19, BAX P19, MCL-1 S 19; Santa Cruz, Santa Cruz, CA, USA) were diluted in Tris buffered saline (TBS) and applied as primary antibodies for 1 hour at a concentration of $1: 100$ (BCL-2) or 1:1000 (BCL-X, BAX, MCL-1). Biotinylated secondary antibodies, either monoclonal to mouse IgG (Dakopatts) or polyclonal to antirabbit IgG (Dakopatts) were both diluted 1:400 in TBS and incubated for 30 minutes to the respective primary antibodies. Streptavidinbiotin horseradish peroxidase complex (Dakopatts) was diluted 1:200 in TBS+albumin and incubated for 30 minutes. Labelled antigens were visualised by application of diaminobenzidine for 10 minutes. Negative controls without primary antibody were done for each probe. All sections were counterstained with haematoxylin. 

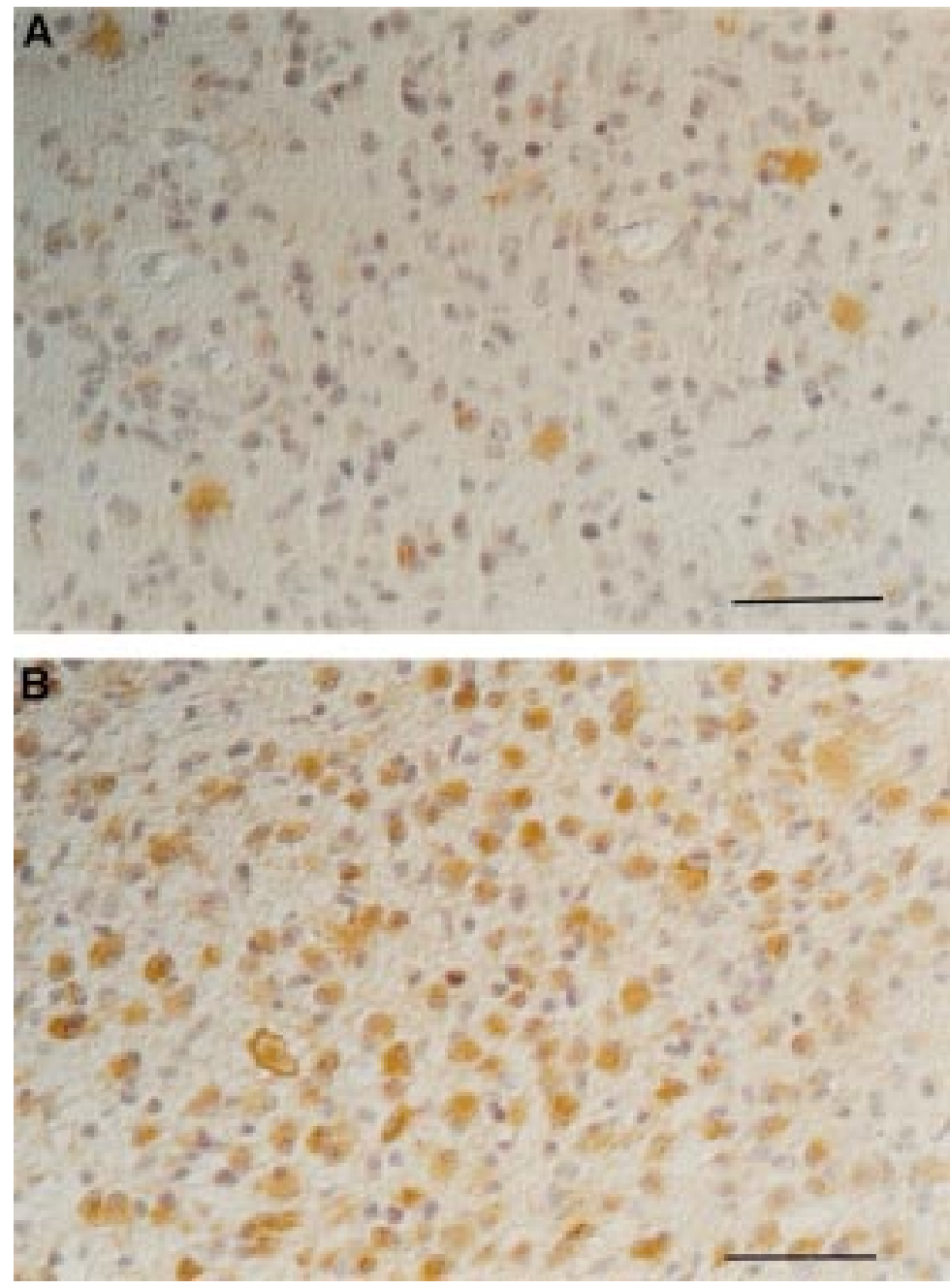

Figure 1 (A) In the primary tumour only single cells are immunolabelled with BCL-2. (B) The recurrent tumour of the same patient, by contrast, is characterised by more than $50 \%$ positive cells (magnification $\times 400$, scale bar $=50 \mu \mathrm{m}$ ).

\section{STATISTICAL ANALYSIS}

For evaluation of the protein expression, 10 high power fields were assessed with the following score: score $1=0-5 \%$ stained cells, score $2=5-$ $50 \%$ stained cells, score $3>50 \%$ stained cells.

For each protein and each patient, cumulative scores of the 10 high power fields were calculated in primary and recurrent tumour. Cumulative score 10 was classified negative, ${ }^{13}$ scores $11-14$ as weak expression, $15-20$ as intermediate, and scores $>20$ were classified as strong expression.
To assess changes in protein expression, the cumulative scores were compared for each protein with the Wilcoxon test for paired probes in all initial and recurrent tumours and in the three treatment groups. In the subgroups, we adjusted the significance level of the $p$ values with the Bonferroni method for multiple significance testing and presumed $\mathrm{p}$ values $<0.017$ (three subgroups: $\alpha=0.05 / 3=0.0166$ ) to be significant at the 0.05 level. The differences between the median cumulative scores in primary and recurrent tumour in the three treatment groups (untreated, radiotherapy, radiochemotherapy) were compared for each protein with the Kruskal-Wallis test to allow a descriptive analysis of the influence of different treatment modalities.

To estimate the influence of protein expression on the clinical prognosis, progression free survival was determined as the time between first and second resection in each case. Median progression free survival was calculated with the Kaplan-Meier method and confirmed with the logrank test in pooled subgroups (for instance, negative and weak expression compared with intermediate and strong expression of BCL-2 ( fig 1).

\section{Results}

STAINING PATTERNS

All antibodies showed mainly cytoplasmic staining, but with BCL-2 and BCL-X, nuclear staining was also seen. Antibodies to BCL-X and to BCL-2 stained strongly. Staining was predominantly homogeneous, but with BAX, a granular pattern also occurred.

PROTEIN EXPRESSION

We found BCL-2 positivity in a high percentage of initial $(34 / 37(92 \%))$ and recurrent $(36 / 37(97 \%))$ tumours. The percentage of protein expressing cells was up regulated at recurrence. This difference was statistically significant in the whole series and in the subgroup with postoperative therapy (also after adjustment with the Bonferroni method in the subgroups, see statistical analysis). Staining in neoplastic gemistocytes accounted predominantly for this rise in protein expression in the recurrent tumours, as could be seen morphologically as well as in the statistical analysis (positive correlation between the rise in BCL-2 expression and content of gemistocytes between first and second resection, $\mathrm{p}=0.0022$ ).

Table 3 Protein expression: median cumulative scores, quartiles (25\% and $75 \%$ percentiles), and $p$ values

\begin{tabular}{|c|c|c|c|c|c|c|c|c|}
\hline & \multicolumn{2}{|l|}{$B C L-2$} & \multicolumn{2}{|l|}{$B C L-X$} & \multicolumn{2}{|l|}{$B A X$} & \multicolumn{2}{|l|}{$M C L-1$} \\
\hline & Initial & Recurrence & Initial & Recurrence & Initial & Recurrence & Initial & Recurrence \\
\hline Whole group $(\mathrm{n}=37)$ & 15 & 19 & 20 & 25 & 14 & 11 & 10 & 11 \\
\hline Quartiles & $13-16$ & $16-22$ & $15-23$ & $23-29$ & $11-15$ & $10-12$ & $10-11$ & $10-13$ \\
\hline $\mathrm{p}$ Value & $<0.0001$ & & $<0.0001$ & & $<0.0001$ & & 0.0395 & \\
\hline Radiochemoth $(n=15)$ & 14 & 19 & 18 & 25 & 12 & 11 & 10 & 11 \\
\hline Quartiles & $12.5-15$ & $17.5-20.5$ & $12-24$ & $22-28$ & $10.5-16$ & $10-11$ & $10-11.5$ & $10-13$ \\
\hline $\mathrm{p}$ Value & 0.0012 & & 0.0031 & & 0.0122 & & 0.0977 & \\
\hline Radiotherapy $(n=15)$ & 15 & 17 & 20 & 22 & 14 & 12 & 10 & 11 \\
\hline Quartiles & $13-18$ & $15.5-22.5$ & $15-23$ & $17.5-30$ & $11-14$ & $10.5-13$ & $10-11$ & $10.5-13$ \\
\hline $\mathrm{p}$ Value & 0.0125 & & 0.081 & & 0.2402 & & 0.0186 & \\
\hline Untreated $(n=7)$ & 15 & 22 & 22 & 29 & 15 & 12 & 11.00 & 11.00 \\
\hline Quartiles & $14-16$ & $14-26$ & $19-24.5$ & $24.5-29.5$ & $11.5-16.5$ & $12-15$ & $11-15.5$ & $11-13.5$ \\
\hline $\mathrm{p}$ Value & 0.0781 & & 0.3125 & & 0.4375 & & 0.6250 & \\
\hline
\end{tabular}

According to the Bonferroni method, only p values $<0.017$ are presumed to be significant at the 0.05 level in the subgroups. 

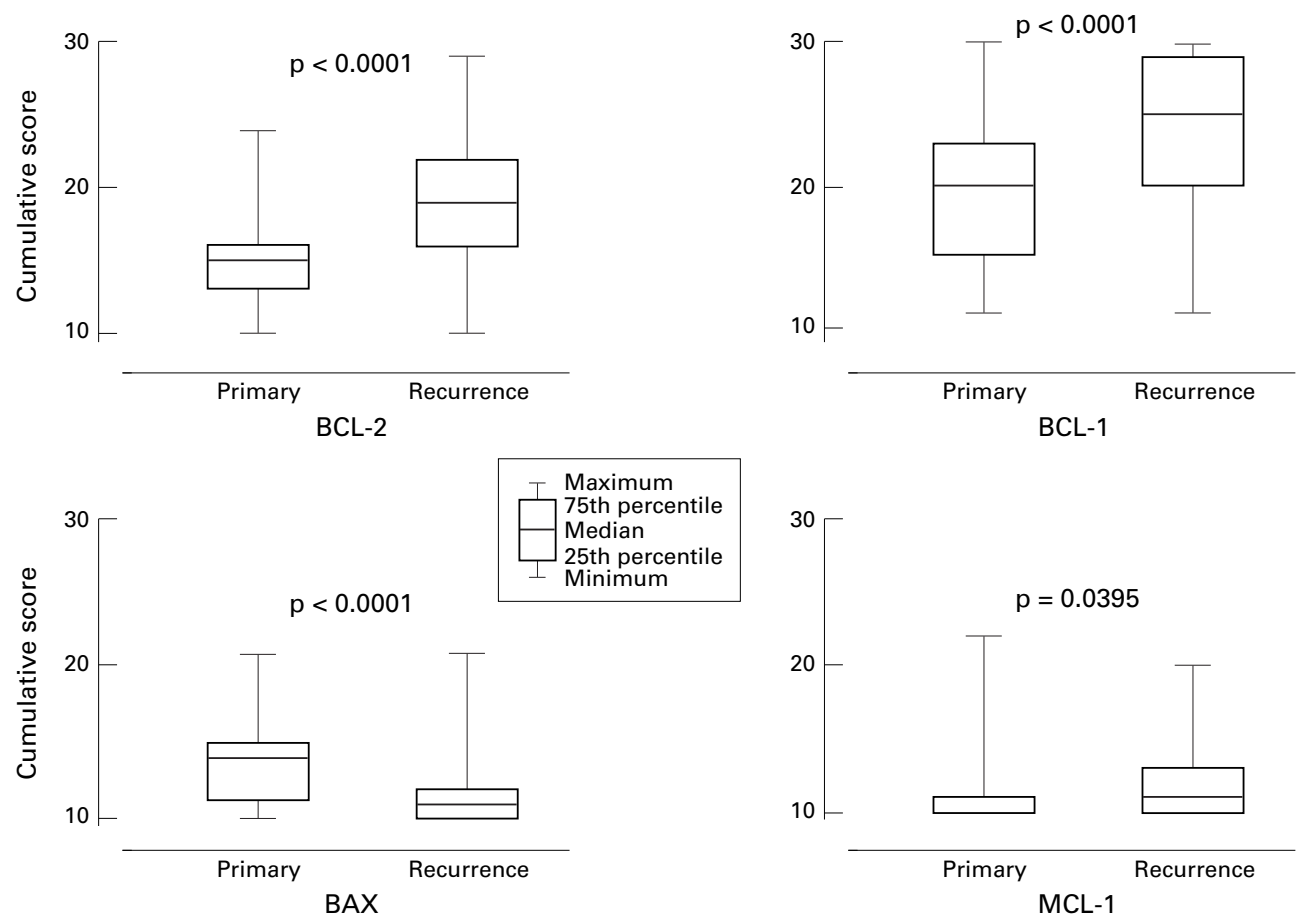

Figure 2 Median cumulative scores of protein expression in the whole group.
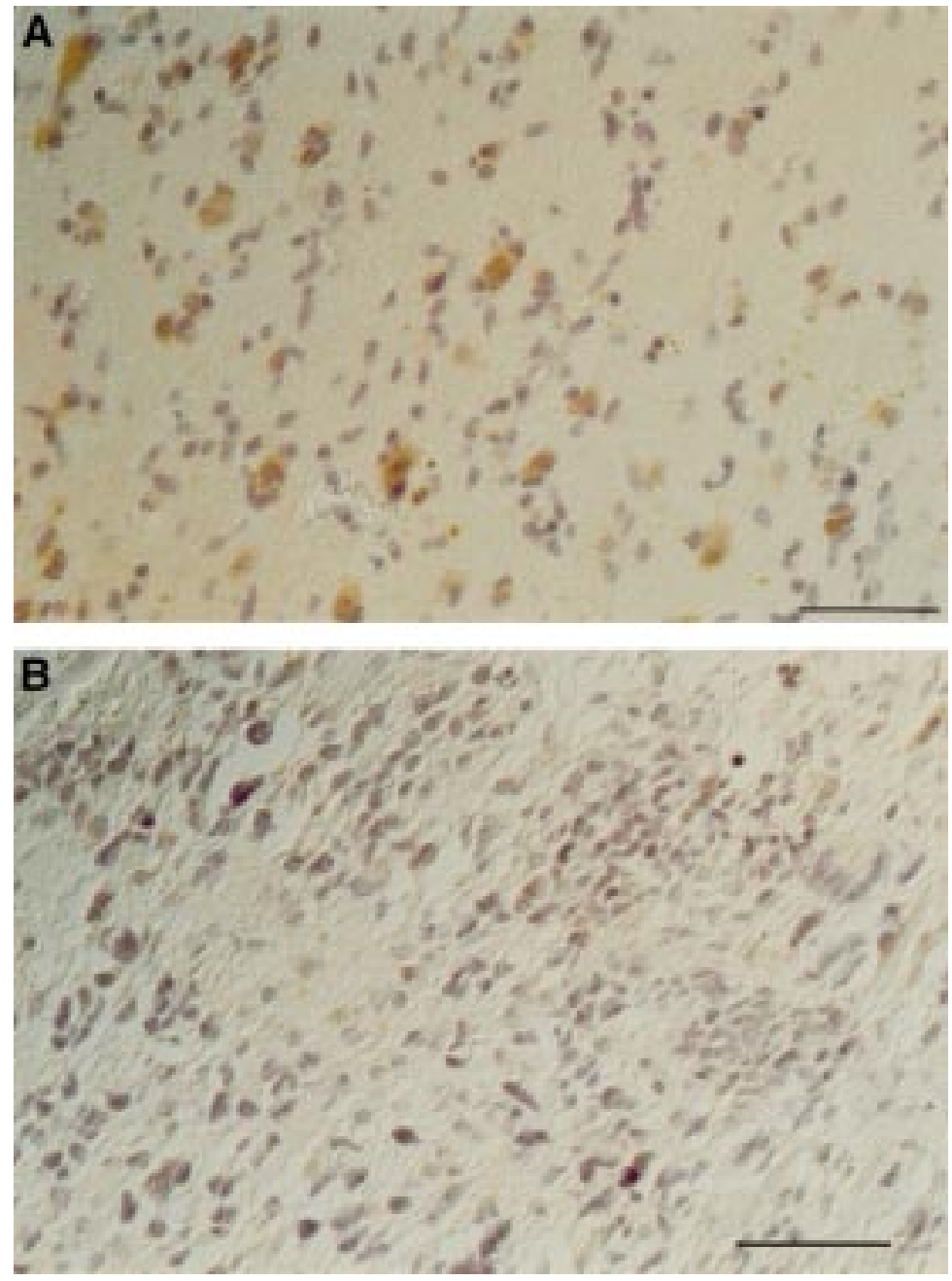

Figure 3 (A) Immunostaining with BAX in the primary tumour shows several positive cells; (B) all cells are negative in the recurrent tumour.
In the group without adjuvant therapy, the same trend towards up regulation of BCL-2 was found but this did not achieve significance (table 3, figs 1 and 2).

BCL-X was expressed in all (100\%) examined initial and recurrent tumours. As with BCL-2, expression was up regulated in all subgroups at recurrence. The differences were significant in the whole series and in the radiochemotherapy group, and the same trend was present in irradiated and untreated patients.

Expression of BAX was found in $31 / 37$ initial $(84 \%)$ and $27 / 37$ recurrent $(73 \%)$ tumours. The percentage of protein expressing cells was down-regulated in all subgroups at recurrence, with a significant difference in the whole series and in the radiochemotherapy group (figs 2 and 3) and with a similar trend in irradiated and untreated patients.

Only $17 / 37$ initial tumours (46\%) and $11 / 37$ relapsed tumours (30\%) were positive for MCL-1. The up-regulation was less pronounced compared with the other proteins and the difference achieved significance in the whole series but not in the subgroups.

Comparing the treatment groups, no significant difference in the up-regulation or downregulation of any protein was found between primary and recurrent tumour. The statistical analysis, however, shows that significant changes in protein expression occurred in the radiochemotherapy groups for BCL-2, BCL-X, and BAX and in the radiotherapy group for BCL-2, but not in the other treatment groups (table 3).

CORRELATION WITH PROGRESSION FREE SURVIVAL Median progression free survival was 9 months in the whole group, 12 months in patients with radiochemotherapy, 11 months with radiotherapy alone, and 6 months in untreated 


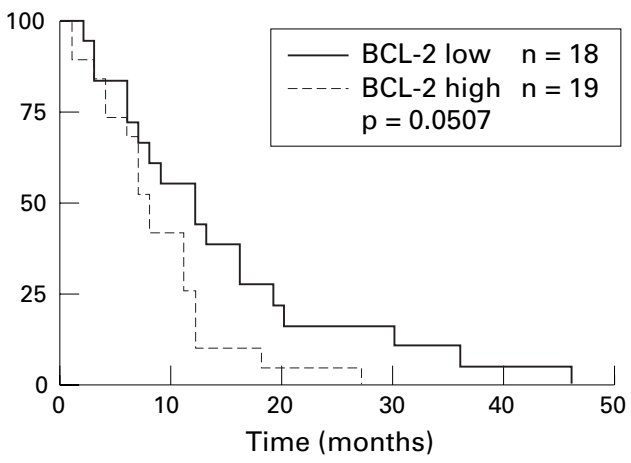

Figure 4 Progression free survival in patients with low and high BCL-2 expression.

patients. In patients with initially negative or weak expression of BCL-2, median progression free survival was 12 months, compared with 8 months with intermediate and strong expression of BCL-2. This difference did not achieve significance $(p=0.0507$, fig 4$)$. Also with all other examined proteins, no significant correlation between protein expression and progression free survival was found (data not shown).

\section{Discussion}

In the present study, we compared the expression of BCL-2 family proteins in initial and recurrent glioblastoma multiforme to assess whether in vitro findings on the contribution of these proteins to the resistance to irradiation and chemotherapy can be endorsed by in vivo data.

The frequency of BCL-2, BCL-X, and BAX expression in our primary tumours corresponds with other series. ${ }^{8-17}$ Compared with the other proteins, MCL-1 was expressed less often in our series $(48 \%)$ and our previous study $(65 \%),{ }^{17}$ whereas other authors had $100 \%$ positivity. ${ }^{18}$ In the recurrent tumours, we found a significant up-regulation of the antiapoptotic proteins BCL-2, BCL-X, and MCL-1 and a significant down-regulation of proapoptotic BAX. Short term effects of chemotherapy on BCL-2 concentrations in vitro have been reported, with divergent results. ${ }^{18-23}$ No reports exist on BCL-2 family protein expression in recurrent, untreated human cancer and no data have been reported on their expression in human glioblastoma multiforme before and after adjuvant therapy. In non-CNS tumours, no change in BCL-2 expression was found in 29 patients with breast cancer after chemotherapy and in 27 patients with colorectal carcinoma after radiotherapy. ${ }^{23}{ }^{24}$ Tumour type specificity may account for the difference between our results and those in other solid tumours. Our findings of a correlation between the up regulation of BCL-2 and the content of gemistocytes is in line with a previous report on predominant expression of BCL-2 in gemistocytes. ${ }^{16}$ The authors suggest that this may result from an accumulation of gemistocytes that escape apoptosis by BCL-2 overexpression, a hypothesis which is supported by our data.

In accordance with other series, ${ }^{8-12}$ we found no significant association between clinical prognosis and expression of BCL-2, BCL-X, or BAX. Also with MCL-1, there was no correlation with prognosis.

Our in vivo findings indicate a shift of the BCL-2 rheostat towards resistance to apoptosis in the recurrent glioblastomas. This may be achieved by a positive selection of cells with enhanced antiapoptotic capacity. One possible mechanism of selection is anticancer treatment, consisting of irradiation and chemotherapy. We found, however, the same tendency to higher expression of antiapoptotic BCL-2 related proteins and a reduction on BAX expression in never treated patients (table 1), indicating that the development of a more apoptosis resistant phenotype cannot only be a consequence of adjuvant radiochemotherapy but may reflect a natural process of selection. These findings are in line with two other features of glioblastoma: (1) most of these tumours show only a moderate response to adjuvant therapy, favouring primary resistance rather than acquired resistance through selection; (2) tumour hypoxia is a prominent feature of glioblastoma and would be predicted to select for the changes characterised here..$^{25-27}$

We are indebted to Dr Barbara Pietsch-Breitfeld from the Institute for Medical Information Processing, Tübingen, for important contributions to the statistical analysis.

1 Walker MD, Alexander E Jr, Hunt WE, et al. Evaluation of $\mathrm{BCNU}$ and/or radiotherapy in the treatment of anaplastic gliomas. A co-operative clinical trial. $f$ Neurosurg 1978;49:333-43.

2 Hirakawa K, Suzuki K, Ueda S, et al. Multivariate analysis of factors affecting postoperative survival in malignant astrocytoma. Importance of DNA quantification. $\mathcal{F} \mathrm{Neu}$ rooncol 1984;2:331-40.

3 Weller M. Predicting response to cancer chemotherapy: the role of p53. Cell Tissue Res 1998;292:435-45.

4 Boise LH, Gonzalez-Garcia M, Postema CE. BCL-x, a $\mathrm{BCL}-2$ related gene that functions as a dominant regulator of cell death. Cell 1993;74:597-660.

5 Oltvai ZN, Milliman CL, Korsmeyer SJ. Bcl-2 heterodimerizes in vivo with a conserved homolog, BAX, that accelerates programmed cell death. Cell 1993;74: 609-19.

6 Weller M, Malipiero U, Aguzzi A, et al. Protooncogene BCL-2 gene transfer abrogates Fas/APO 1 antibody mediated apoptosis of human malignant glioma cells and confers resistance to chemotherapeutic drugs and theraconfers resistance to chemotherapeutic drugs and
peutic irradiation. $\mathcal{f}$ Clin Invest 1995;95:2633-43.

7 Weller M, Winter S, Schmidt C, et al. Topoisomerase I inhibitors for human malignant glioma: differential modulation of p53, p21, BAX and BCL 2 expression and of CD95 mediated apoptosis by camptothecin and beta lapachone. Int $\mathcal{F}$ Cancer 1997;73:707-14.

8 Nakasu S, Nakasu Y, Nioka H, et al. BCL 2 protein expression in tumours of the central nervous system. Acta Neuropathol 1994;88:520-6.

9 Schiffer D, Cavalla P, Migheli A, et al. BCL-2 distribution in neuroepithelial tumours: an immunohistochemical study. $\mathcal{F}$ Neurooncol 1996;27:101-9.

10 Newcomb EW, Bhalla SK, Parrish CL, et al. Bcl-2 protein expression in astrocytomas in relation to patient survival and p53 gene status. Acta Neuropathol 1997;94:369-75.

11 Newcomb EW, Cohen H, Lee SR, et al. Survival of patients Newcomb EW, Cohen $\mathrm{H}$, Lee SR, et al. Survival of patients
with glioblastoma multiforme is not influenced by altered expression of p16, p53, EGFR, MDM2 or BCL-2 genes. expression of p16, p53, EGFR,
Brain Pathol 1998;8:655-67.

12 Rieger L, Weller M, Bornemann A, et al. BCL 2 family protein expression in human malignant glioma: a clinicopathological correlative study. F Neurol Sci 1998;155:68-75.

13 Alderson LM, Castleberg RL, Harsh GR, et al. Human gliomas with wild type p53 express bcl 2. Cancer Res 1995;55: 999-1001.

14 Ellison DW, Steart PV, Gatter KC, et al. Apoptosis in cerebral astrocytic tumours and its relationship to expression of the BCL 2 and p 53 proteins. Neuropathol Appl Neurobiol 1995;21:352-61.

15 Krishna M, Smith TW, Recht LD. Expression of BCL 2 in reactive and neoplastic astrocytes: lack of correlation with presence or degree of malignancy. $\mathcal{F}$ Neurosurg 1995;83: presence

16 Watanabe K, Tachibana O, Yonekawa Y, et al. Role of gemistocytes in astrocytoma progression. Lab Invest 1997;76: 277-84. 
17 Krajewski S, Krajewska M, Ehrmann J, et al. Immunohistochemical analysis of BCL 2, BCL X, MCL-1, and BAX in tumours of central and peripheral nervous system origin. Am f Pathol 1997;150:805-14.

18 Simonian PL, Grillot DAM, Merino R, et al. BAX can antagonize BCL XL during etoposide and cisplatin induced cell death independently of its heterodimerization with BCL XL. F Biol Chem 1996;271:22764-72.

$19 \mathrm{Tu} \mathrm{Y}, \mathrm{Xu} \mathrm{FH}$, Liu J, et al. Upregulated expression of BCL2 in multiple myeloma cells induced by exposure to doxoruin multiple myeloma cells induced by exposure to doxorubicin, etop

20 Ikeguchi M, Tatebe S, Kaibara N, et al. Changes in levels of expression of p53 and the product of the BCL-2 in lines of gastric cancer cells during cisplatin induced apoptosis. Eur Surg Res 1997;29:396-402.

21 Ogretmen B, Safa AR. Down regulation of apoptosis related BCL-2 but not BCL-xL or BAX proteins in multidrug resistant MCF 7/Adr human breast cancer cells. Int 7 Cancer 1996;67:608-14.
22 Sakakura C, Sweeney EA, Shirahama T, et al. Overexpression of BAX sensitized human breast cancer MCF 7 cells to radiation induced apoptosis. Int $\mathcal{F}$ Cancer 1996;67:101-5.

23 Frassoldati A, Adami F, Banzi C, et al. Changes of biological features in breast cancer cells determined by primary chemotherapy. Breast Cancer Res Treat 1997;44:185-92.

24 Palazzo JP, Kafka NJ, Grasso L, et al. The role of p53, p21WAF1/C1PI, and BCL-2 in radioresistant colorectal carcinoma. Hum Pathol 1997;28:1189-95.

25 Tsujimoto Y, Shimizu S, Eguchi Y, et al. BCL 2 and BCL xL block apoptosis as well as necrosis: possible involvement of common mediators in apoptotic and necrotic signal transduction pathways. Leukemia 1997; 11 (suppl 3):380-2.

26 Shimizu S, Eguchi Y, Kamiike W, et al. Induction of apoptosis as well as necrosis by hypoxia and predominant prevention 56:2161-6.

27 Graeber TG, Osmanian C, Jacks T, et al. Hypoxia mediated selection of cells with diminished apoptotic potential in solid tumours. Nature 1996;379:88-91. 